\title{
Evaluation of spirometry indications for patients in a tertiary hospital in Turkey and validity of spirometry findings in patients with COPD
}

\author{
Ozlem SENGOREN DIKIS ${ }^{1}$, Hakan DEMIRCI ${ }^{2}$, Ismail KABA ${ }^{2}$, Can MUGAN², Miktat Arif HABERAL ${ }^{3}$, Ozge ORAN TAPAN $^{4}$ \\ ${ }^{1}$ Department of Pulmonary Medicine, Bursa City Hospital, Bursa, TURKEY \\ 2 Department of Family Medicine, University of Health Sciences Turkey Bursa Yuksek Ihtisas Training and Research Hospital, Bursa, TURKEY \\ ${ }^{3}$ Department of Thoracic Surgery, University of Health Sciences Turkey Bursa Yuksek Ihtisas Training and Research Hospital, Bursa, TURKEY \\ ${ }^{4}$ Department of Pulmonary Medicine, Mugla Sitki Kocman University, Mugla, TURKEY
}

\section{ABSTRACT}

Aim: Diseases of the respiratory system are among the most common medical conditions and cause considerable morbidity and mortality. This study aimed to identify the indications for spirometry in a tertiary hospital in Turkey and validity of spirometry findings in patients with COPD.

Methods: A total of 1551 patients were included in the study. Spirometry testing (FEV1, FCV and FEV1/FCV) was performed in the pulmonary function test unit. The height and weight of the patients were also recorded.

Results: The most common reasons for performing spirometry were to evaluate symptoms, signs and laboratory results $(55.1 \%, n=854)$, to decide on treatment approaches $(55 \%, n=853)$ and to determine the course of the disease $(12.7 \%, n=197)$. The most common conditions diagnosed were asthma $(25 \%, n=388)$, seasonal allergic rhinitis $(23 \%, n=356)$, cough $(15.2 \%, n=235)$, bronchitis $(12.4 \%, n=193)$ and dyspnea $(11.4 \%, n=177)$. The areas under the curve (AUC) values for FEV1/FVC, FEV1 and FCV in predicting chronic COPD were $0.77,0.73$ and 0.66 , respectively. The cut-off point for FEV1/FVC was $78.4 \%$. The sensitivity and specificity of the FEV1/FVC ratio for predicting COPD were calculated as $67.4 \%$ and $79.1 \%$, respectively.

Conclusions: In this study, we determined that the physicians' indications for spirometry deemed appropriate in our region. Although spirometry indications vary, physicians mostly used spirometry to determine the severity of the disease and the diagnosis. Physicians ordering pulmonary function tests and diagnosing chest conditions from these tests should be updated regularly to prevent misdiagnosing.

Keywords: Chronic Obstructive Pulmonary Disease, Forced Expiratory Volume, Forced Vital Capacity, Pulmonary Function Tests

Corresponding Author: Can MUGAN can mugan@hotmail.com

Received: November 18, 2021; Accepted: December 02, 2021; Published Online: December 31, 2021

Cite this article as: Sengoren Dikis, O., Demirci, H., Kaba, I., Mugan, C., Haberal, M. A., \& Oran Tapan, O. (2021). Evaluation of spirometry indications for patients in a tertiary hospital in Turkey and validity of spirometry findings in patients with COPD. European Journal of Human Health 1(3), 115-124. 


\section{Introduction}

Diseases of the respiratory system are among the most common medical conditions and lead to considerable morbidity and mortality $(1,2)$. The department of chest diseases is responsible for pulmonary symptoms/diseases including asthma, chronic obstructive pulmonary disease (COPD), bronchitis, emphysema, cystic fibrosis, pneumonia, tuberculosis, pulmonary edema, lung cancer, acute respiratory distress syndrome (ARDS), pneumoconiosis, interstitial lung disease, pulmonary embolism, pulmonary hypertension, pleural effusion, pneumothorax, mesothelioma, obesity hypoventilation syndrome and neuromuscular lung disease. Amongthese ailments, the prevalence of asthma and COPD is on the increase all over the world, especially in middle- and low-income countries, reaching up to 300-600 million people $(1,3)$.

Today, $66 \%$ of deaths occur due to chronic diseases. In addition, cardiovascular disease, cancer, chronic respiratory disease and diabetes constitute $80 \%$ of all chronic diseases (4). For a decade, respiratory conditions have been the third most common cause of death, in the range of $9 \%$ to $12.5 \%$ in Turkey. Of the total 421164 deaths in 2018, 52568 were due to respiratory diseases. Furthermore, approximately $60 \%$ of these deaths were due to COPD (5).

Clinical pulmonary function tests (PFTs) play a crucial role in the management of respiratory diseases. PFTs provide not only objective lung function evaluations but also yield reproducible and quantitative results, allowing longitudinal monitoring. This feature of PFTs is quite essential since respiratory symptoms correlate poorly with disease severity and progression $(1,6$, 7).On the other hand, spirometry is a relatively cheap, basic, well-tolerated, widely used and non-invasive PFT that measures the volume of air inhaled or exhaled $(8,9)$. It mainly evaluates lung volumes and flows and plays a critical role in the diagnosis, monitoring, differentiation and management of most pulmonary diseases, such as asthma, COPD and other restrictive lung disorders $(1,8,10)$. In addition, it can evaluate the possible effects of diseases of other organs/systems on lung function. Thus, spirometry should constitute an integral component of any routine health examination, especially with pulmonary diseases $(1,11)$.

Some of the indications for spirometry are "evaluation of the presence/absence of a lung disease", "investigation of the effect of disease on pulmonary functions", "determination of the preoperative risk", "monitoring occupational exposure", "determination of disabilities", and "comparison of the health status of societies" $(1,8,12-14)$. This study aimed to identify the indications for spirometry in a tertiary hospital in Turkey and validity of spirometry findings in patients with COPD.

\section{Methods}

\section{Study design}

This was a prospective, observational, analytical, cross-sectional study. The study was approved by the Ethics Committee of the Health Sciences University, Bursa Yuksek Ihtisas Education and Research Hospital (Approval date: 26.07.2018; number: 2011-KAEK-25 03/26).

\section{Setting}

The study was conducted at the Pulmonary Function Test (PFT) unit of the Chest Disease Clinics of Bursa Yuksek Ihtisas Training and Research Hospital between April 1 and May 31, 2018. The PFT unit accepts requests from hospital doctors by appointment. An application is made by completing a referral form on the computer system. The PFT unit applies only simple spirometry testing. 


\section{Participants}

In the study period, a total of 1595 patients were referred to the PFT unit. Of these, 1556 accepted to join the study. Four patients were excluded from the analysis due to non-compliance and one because of recent myocardial infarction. So, we carried the study with 1551 participants.

\section{Variables}

The most essential data provided by the spirometer are the Forced Vital Capacity (FVC) and Forced Expiratory Volume in one second (FEV1). On the other hand, spirometry has defined indications that are varied and depend on the clinical settings and questions. In this study, we used the classification mentioned by García-Río et al. (8).

Spirolab-II MIR 010, a product of Medical International Research (MIR), was used as a spirometry device. The device uses a disposable filter mouthpiece. Pulmonary function parameters, such as Forced Expiratory Volume in 1 second (FEV1) (\% of predicted), Forced Vital Capacity (FVC), FEV1/FVC\% and peak expiratory flow (PEF) were recorded. Pulmonary function was tested at baseline and post-inhaling bronchodilator. For the reversibility test, spirometric measurements were done before and 20 minutes after inhalation of $400 \mu \mathrm{g}$ salbutamol with a metered dose inhaler. In the evaluation of bronchodilator response, reversibility was calculated based on the expected FEV1 percentage of $12 \%$ and the absolute change between both FEV1 measurements as over $200 \mathrm{ml}$.

Also, height and weight of the patients were measured with standard calibrated devices, and Body Mass Index (BMI) values were calculated using the "weight $(\mathrm{kg}) /$ height $(\mathrm{m})^{2 \prime \prime}$ formula.

Demographic data of the patients, the reason for testing and the primary clinical differential diagnosis were obtained from the referral form. After the PFT procedure, the clinical diagnosis of the referring doctor was obtained from the patients' electronic medical records. Patients who could not complete the spirometer test or who were noncompliant were excluded from the study $(n=4)$. Additionally, spirometry test was not performed for patients who had a myocardial infarction (MI) within the last month $(n=1)$.

\section{Bias}

Spirometric evaluation can be accomplished with many different devices. However, standardization has been suggested to ensure that the obtained results have not been affected by technical and personal factors. In this study, we used the American Thoracic Society (ATS) and European Respiratory Society (ERS) spirometer standardization guidelines, prepared in 2005 (9). Additionally, to prevent bias, two nurses working in the PFT unit were trained according to the guidelines before starting the study.

\section{Study size}

A sample size calculation was performed, targeting to estimate FVC in a population of an unknown quantity with a $95 \%$ confidence interval. Taking the standard deviation as 1 liter, a sample size of 1497 patients was required to estimate FVC with a margin of error of 0.1 . The calculation was done with the web-based online Java applet developed by Russ Lenth (https://homepage.divms.uiowa.edu/ rlenth/Power/).

\section{Statistical methods}

Statistical analysis was performed with the Statistical Package for the Social Sciences version 21 (SPSS, IBM, Armonk, NY, USA). The "number," "percentage," "mean" and "standard deviation" were used for descriptive statistics of the continuous variables. Independent samples t-test or Mann-Whitney $U$ test were used to compare two independent groups. Pearson Chi-Square or Fisher's exact tests were used 
to analyze categorical data. The cut-off point for the validity of spirometry in the diagnosis of COPD was determined using the receiver operating characteristic (ROC) curve. Results were evaluated with a confidence interval of $95 \%$, and the level of significance, $p$, was set at 0.05 .

\section{Results}

Data for 1551 patients were analyzed. The gender distribution was in favor of women. The majority of the participants were smokers. Demographic information of the participants and the distribution of the mean PFT values are summarized in Table 1.

Table 1: Distribution of demographic information of the participants

\begin{tabular}{|c|c|}
\hline & $n=1551$ \\
\hline Age (year) (mean $\pm S D)$ & $46.78 \pm 16.95$ (min:16, max:92) \\
\hline \multicolumn{2}{|l|}{ Gender } \\
\hline Female & $861(55.50 \%)$ \\
\hline Male & $690(44.50 \%)$ \\
\hline BMI (mean士SD) & $28.29 \pm 6.30(\min : 13.79, \max : 62.64)$ \\
\hline \multicolumn{2}{|l|}{ Smokingstatus } \\
\hline Smoker & $820(52.9 \%)$ \\
\hline Non-smoker & 731 (47.1\%) \\
\hline \multicolumn{2}{|l|}{ PFT Results (mean $\pm S D$ ) } \\
\hline FVC & $3.09 \pm 1.17(\min : 0.18, \max : 6.92)$ \\
\hline FVC \% & $85.18 \pm 20.38(\min : 8, \max : 250)$ \\
\hline FEV1 & $2.61 \pm 2.43(\min : 0.18, \max : 89.50)$ \\
\hline FEV1 \% & $84.54 \pm 23.37(\min : 1.12, \max : 384)$ \\
\hline FEV1/FVC & $82.21 \pm 10.60(\min : 1.60, \max : 100)$ \\
\hline$P E F$ & $4.98 \pm 2.11(\min : 0.22, \max : 11.65)$ \\
\hline PEF \% & $67.32 \pm 22.19(\min : 3, \max : 130)$ \\
\hline
\end{tabular}

Table 2 shows the distribution of the indications. The total number of indications was 2471. As seen in Table
2, the most common reasons for performing spirometry were "symptoms, signs and laboratory results," "determination of treatment approaches," and "determination of the course of the disease." 
Table 2: Indication distribution of the participants

\begin{tabular}{|c|c|}
\hline & $n=1551$ \\
\hline \multicolumn{2}{|l|}{ Diagnosis } \\
\hline To evaluate symptoms, signs and abnormal laboratory tests & $854(55.1 \%)$ \\
\hline To investigate the effect of disease on pulmonary functions & $166(10.7 \%)$ \\
\hline To screen individuals at risk of having pulmonary disease & $118(7.6 \%)$ \\
\hline To determine preoperative risk & $144(9.3 \%)$ \\
\hline To determine prognosis & 0 \\
\hline To determine general health status before beginning strenuous exercise & $2(0.1 \%)$ \\
\hline \multicolumn{2}{|l|}{ Monitoring } \\
\hline To determine therapeutic interventions & $853(55 \%)$ \\
\hline To describe the course of the disease affecting lung function & $197(12.7 \%)$ \\
\hline To monitor occupational exposure & $1(0.1 \%)$ \\
\hline To monitor side effects of drugs with pulmonary toxicity & 0 \\
\hline \multicolumn{2}{|l|}{ Disability } \\
\hline To evaluate patients as part of a rehabilitation program & $134(8.60 \%)$ \\
\hline To evaluate risks in terms of medical insurance & $134(8.60 \%)$ \\
\hline To evaluate individuals for legal reasons & $135(8.70 \%)$ \\
\hline \multicolumn{2}{|l|}{ Public health } \\
\hline Epidemiological surveys & $1(0.10 \%)$ \\
\hline To compare the health status of societies living in different environments & $1(0.10 \%)$ \\
\hline To evaluate complaints caused by occupational or environmental factors & $1(0.10 \%)$ \\
\hline Total & 2471 \\
\hline
\end{tabular}

Note: There was more than one indication in some cases.

A total of 1711 diagnoses were made. When the diagnostic distribution of participants was evaluated, the most common diseases for patients with spirometry indications were asthma, seasonal allergic rhinitis, cough, bronchitis and dyspnea. The least diagnosed condition was lower respiratory tract infection (Table 3). 
Table 3: Distribution of the diagnoses

\begin{tabular}{|l|l|}
\hline & $\mathbf{n = 1 5 5 1}$ \\
\hline Asthma & $388(25.0 \%)$ \\
\hline Seasonal allergic rhinitis (SAR) & $356(23.0 \%)$ \\
\hline Cough & $235(15.2 \%)$ \\
\hline Bronchitis & $193(12.4 \%)$ \\
\hline Dyspnea & $177(11.4 \%)$ \\
\hline Chronic Obstructive Pulmonary Disease (COPD) & $135(8.7 \%)$ \\
\hline Dependence on tobacco use & $114(7.4 \%)$ \\
\hline Pneumonia & $46(3.0 \%)$ \\
\hline Cardiovascular Disease & $39(2.5 \%)$ \\
\hline Upper Respiratory Tract Infection (URTI) & $24(1.5 \%)$ \\
\hline Lower Respiratory Tract Infection (LRTI) & $4(0.3 \%)$ \\
\hline Total & 1711 \\
\hline
\end{tabular}

Note: There was more than one diagnosis in some cases.

We performed ROC analysis to compare the (AUC) for FEV1/FVC ratio, FEV1 and FVC were 0.769 concordance of clinical COPD diagnoses with PFT ( $95 \%$ CI: 0.75 to 0.79 ), 0.729 ( $95 \%$ CI: 0.71 to 0.75 ) results. The receiver-operator characteristic (ROC) curve is seen in Figure 1. The area under the curve and 0.655 (95\% CI: 0.63 to 0.68 ), respectively. All $\mathrm{p}$ values were $<0.001$.

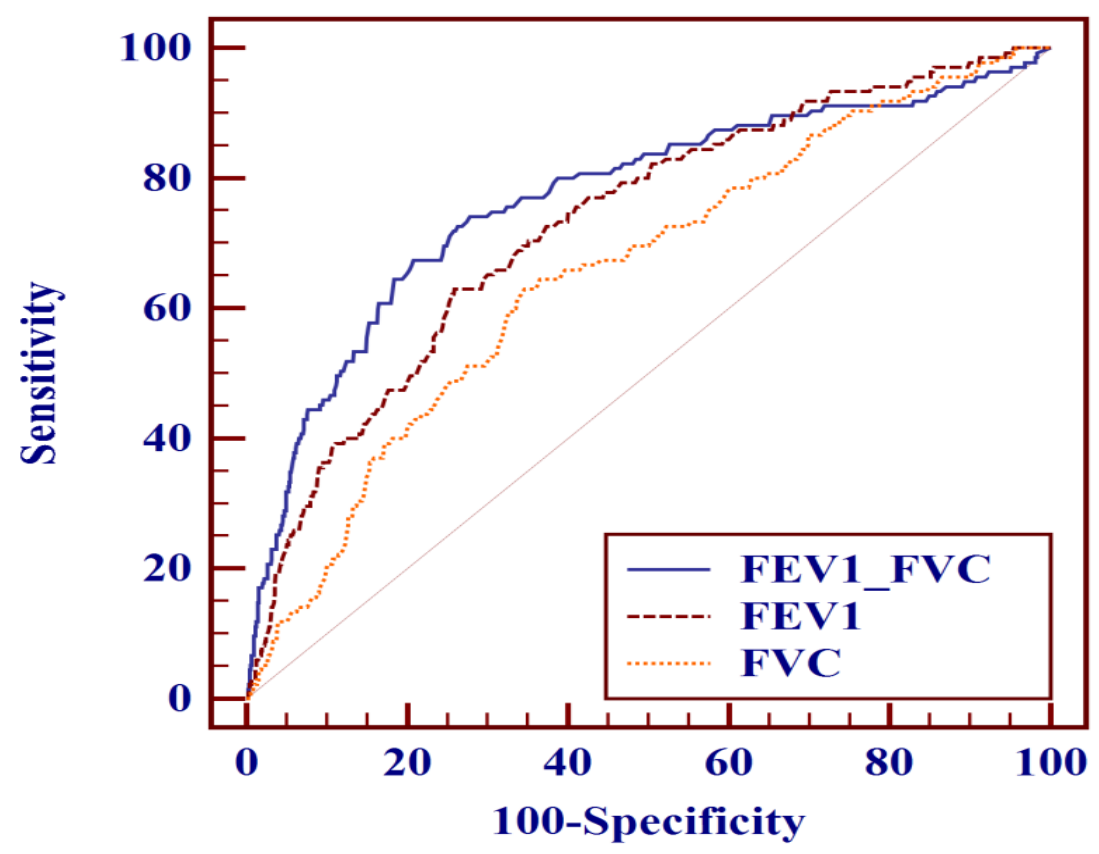

Figure 1: ROC curves for determining the presence of COPD 
Cut-off points for FEV1/FVC, FEV1 and FVC were calculated as $78.4 \%, 1.96 \mathrm{~L}$ and $2.65 \mathrm{~L}$, respectively. The sensitivity and specificity of the FEV1/FVC ratio for predicting COPD were calculated as $67.4 \%$ and $79.1 \%$, respectively. On the other hand, FEV1 had a sensitivity of $62.9 \%$ and a specificity of $74.0 \%$, while FVC demonstrated a sensitivity of $62.9 \%$ and a specificity of $65.4 \%$.

\section{Discussion}

This study demonstrated that the most common reason for ordering spirometry in the studied population was to evaluate symptoms, signs and abnormal laboratory tests. On the other hand, the most common diagnosis was asthma. As a striking feature, there was no total agreement between the diagnoses made by the referring clinicians and the pulmonary function test results.

The anthropometric data of our study is closely similar to related studies. The majority of the patients in our study were below the age of 50 years, which agrees with the findings of similar studies $(3,10,15)$, but differs from a Canadian study (16) in which majority of the patients who underwent spirometry were elderly. This may be because asthma, which is a condition that occurs more frequently below 45 years of age, was the most common indication for spirometry in our center. These results show that all age groups need spirometric assessment, and the indications for spirometry spans across all ages.

D'Andiran et al. (17) stated in their study that of their participants, $51 \%$ were male, and the prevalence of smokers was $40.66 \%$. The majority of patients were male in most of the studies in the literature, and the prevalence of smokers was in a range between 19$52 \%(15,18,19)$. In our study, the smoking rate of patients referred for spirometry was higher than the general literature. Respiratory symptoms become more prominent with tobacco use. Thus, it is expected that tobacco users are more often given spirometry tests.

In this study, the most common reasons for performing spirometry were symptoms, signs and laboratory results, the determination of treatment approaches, and the determination of the course of the disease. Distributions of the most common conditions in patients with spirometric indications were asthma, seasonal allergic rhinitis, cough, bronchitis and dyspnea. It is noteworthy to mention that COPD had a relatively low prevalence among patients with spirometric indications. In contrast to our study, COPD was the most prevalent disease according to spirometric results obtained from other studies (1820). Smoking is a known and strong risk factor for COPD. However, the proportion of COPD patients in our study was $8.7 \%$, which suggests an underdiagnosis of this condition. On the other hand, the most common diagnosis was bronchial asthma (25\%) which is similar to the findings of the studies done by Onyedum et al. (46.3\%) (10), Nwosu et al. (39.4\%) (3) and Neopane et al. (24.2\%) (20).

The reference values in PFTs are based on a statistical analysis of data obtained from large research groups of healthy individuals with no history of lung disease and low exposure to risk factors such as smoking or environmental air pollutants. It has been accepted that $\mathrm{FEV}_{1}$ and FVC vary over time in both healthy persons as well as people with respiratory disease. Anthropometric characteristics such as age, sex, height, ethnicity, body weight and body surface area are variables that have a significant effect on the parameters measured in PFTs (21).Biodiversity of societies, types of equipment used, measurement techniques and statistical models used in data analysis change over time. Alterations in environmental and nutritional conditions, as well as technological 
advances, define the accuracy of the measurements. Since reference values are used in medical decisions, they need to be updated periodically. Otherwise, the predicted values will lose their sensitivity to detect abnormal conditions in young cohorts (22-24). Although no comparison was made according to age groups in our study, FEV1, FVC, FEV1/FVC ratios, and percentages of the present cohort were lower than in Australian and Swiss populations $(25,26)$.

This study evaluated the validity of spirometry findings in patients with COPD with a focus on FEV1, FVC and FEV1/FVC values. The GOLD initiative (15) suggested cut-off points of FEV1/FVC in diagnosing COPD as $<70 \%$ of the expected values. However, in our study, the cut-off point for FEV1/FVC was determined as $\leq 78.1 \%$, which is another indication that COPD is under-diagnosed in our sample. Backman et al. (25) reported FEV1, FVC and FEV1/FVC values in men (4.18, 5.30 and 0.788 , respectively) and women (2.88, 3.66 and 0.785 , respectively) similar to our results. Additionally, Evans et al. (1) determined FEV1, FVC and FEV1/FVC values of 3.69, 4.74, and 77.9, respectively. Also, Kocabas et al. (27) reported FEV1, FVC and FEV1/FVC values in their study as 1.4, 2.2 and 65.3 , respectively.

\section{Limitations}

This study should be interpreted considering some limitations. First, the FEV1/FVC ratio to define COPD decreases with age due to loss of lung elasticity. This criterion should be considered throughout the assessment of indications of spirometry. In addition, a moredetailed, self-reported questionnaire for the assessment of symptoms could have been provided. Also, the comparison of spirometric results with different guideline indication criteria could yield other useful information.

\section{Conclusions}

In this study, we determined that the physicians' indications for spirometry deemed appropriate in our region. Although spirometry indications vary, physicians mostly used spirometry to determine the severity of the disease and the diagnosis.Physicians ordering pulmonary function tests and diagnosing chest conditions from these tests should be updated regularly to prevent misdiagnosing.

\section{Conflict of interest}

The authors declare that there is no conflict of interest. 


\section{References}

1. Evans SE, Scanlon PD. Current practice in pulmonary function testing. Mayo Clin Proc. 2003;78(6):758-63; quiz 63.

2. Mannino DM. COPD: epidemiology, prevalence, morbidity and mortality, and disease heterogeneity. Chest. 2002;121(5 Suppl):121S-6S.

3. Nwosu NI, Chukwuka CJ, Onyedum CC, Odilinye HC, Nlewedim PI, Ayuk AC. Current pattern of spirometry utilisation in a sub-Saharan African country. African Journal of Respiratory Medicine. 2016;12(1):15-20.

4. Lozano R, Naghavi M, Foreman K, Lim S, Shibuya K, Aboyans $\mathrm{V}$, et al. Global and regional mortality from 235 causes of death for 20 age groups in 1990 and 2010: a systematic analysis for the Global Burden of Disease Study 2010. Lancet. 2012;380(9859):2095-128.

5. Turkish Statistics Institute. [Mortality statistics 2018] (in Turkish) [Available from: https://www.tuseb.gov.tr/enstitu/tacese/haber detay.php?id=193.

6. Crapo RO. Pulmonary-function testing. N Engl J Med. 1994;331(1):25-30.

7. Ferguson GT, Enright PL, Buist AS, Higgins MW. Office spirometry for lung health assessment in adults: a consensus statement from the National Lung Health Education Program. Respir Care. 2000;45(5):513-30.

8. García-Río F, Calle M, Burgos F, Casan P, del Campo F, Galdiz JB, et al. Spirometry. Archivos de Bronconeumologica. 2013;49(9):388-401.

9. Miller MR, Hankinson J, Brusasco V, Burgos F, Casaburi R, Coates A, et al. Standardization of spirometry. European Respiratory Journal. 2005;26:319-38.

10. Onyedum CC, Chukwuka CJ. Indications for Spirometryata Tertiary Hospital in South East, Nigeria. Nigerian Journal of Clinical Practice. 2009;12(3):229-31.

11. American Thoracic Society. Standardization of Spirometry. American Journal of Respiratory and Critical Care Medicine. 1994;152:1107-36.

12. Meo SA. Significance of spirometry in diabetic patients. International Journal of Diabetes Mellitus. 2010:47-50.

13. Richards JA. Office spirometry-indications and limitations. South African Family Practice. 2006;48(2):48-51.

14. Sewa DW, Ong TH. Pulmonary Function Test: Spirometry. Proceedings of Singapore Healthcare. 2014;23(1):57-64.

15. Luize AP, Menezes AM, Perez-Padilla R, Muino A, Lopez MV, Valdivia G, et al. Assessment of five different guideline indication criteria for spirometry, including modified GOLD criteria, in order to detect COPD: data from 5,315 subjects in the PLATINO study. NPJ Prim Care Respir Med. 2014;24:14075.

16. Chan B, Anderson G, Dales RE. Spirometry utilization in Ontario: practice patterns and policy implications. CMAJ. 1997;156(2):169-76.

17. d'Andiran G, Schindler C, Leuenberger P. The absence of dyspnoea, cough and wheezing: a reason for undiagnosed airflow obstruction? Swiss Med Wkly. 2006;136(27-28):425-33.

18. Miravitlles $M$, de la Roza $C$, Morera J, Montemayor T, Gobartt E, Martin A, et al. Chronic respiratory symptoms, spirometry and knowledge of COPD among general population. Respir Med. 2006;100(11):1973-80.

19. Vafaei I, Bilan N, Ghasempour M. Validity of Spirometry for Diagnosis of Cough Variant Asthma. International Journal of Pediatrics. 2017;5(12):6431-8.

20. Neopane A, Poudel M, Pradhan B, Regmi $S$, Karki DB. Spirometry in evaluation of respiratory diseases. JNMA J Nepal Med Assoc. 2006;45(164):332-6.

21. Pellegrino R, Viegi G, Brusasco V, Crapo RO, Burgos F, Casaburi R, et al. Interpretative strategies for lung function tests. Eur Respir J. 2005;26(5):948-68. 
22. American Thoracic Society. Lung function testing: selection of reference values and interpretative strategies. American Thoracic Society. Am Rev Respir Dis. 1991;144(5):1202-18.

23. Baur $X$, Isringhausen-Bley $S$, Degens $P$. Comparison of lung-function reference values. Int Arch Occup Environ Health. 1999;72(2):69-83.

24. Roca J, Burgos F, Sunyer J, Saez M, Chinn $S$, Anto JM, et al. References values for forced spirometry. Group of the European Community Respiratory Health Survey. Eur Respir J. 1998;11(6):1354-62.

25. Backman $H$, Lindberg $A$, Sovijarvi $A$, Larsson $\mathrm{K}$, Lundback $B$, Ronmark $E$. Evaluation of the global lung function initiative 2012 reference values for spirometry in a Swedish population sample. BMC Pulm Med. 2015;15:26.

26. Thompson BR, Stanojevic $S$, Abramson MJ, Beasley R, Coates A, Dent A, et al. The all-age spirometry reference ranges reflect contemporary Australasian spirometry. Respirology. 2011;16(6):912-7.

27. Kocabas A, Kara K, Ozgur G, Sonmez H, Burgut R. Value of preoperative spirometry to predict postoperative pulmonary complications. Respiratory Medicine. 1996;90:25-33. 